\title{
Insulin Availability and Affordability in the Urban Municipality of Antananarivo, Madagascar
}

\author{
Sitraka Angelo Raharinavalona*, Rija Eric Raherison, Thierry Razanamparany, \\ Solofo Andrianarivelo Ralamboson, Hanta Marie Danielle Vololontiana, \\ Andrinirina Dave Patrick Rakotomalala
}

Faculty of Medicine, University of Antananarivo, Antananarivo, Madagascar

Email address:

sitrakarah@gmail.com (S. A. Raharinavalona)

${ }^{*}$ Corresponding author

\section{To cite this article:}

Sitraka Angelo Raharinavalona, Rija Eric Raherison, Thierry Razanamparany, Solofo Andrianarivelo Ralamboson, Hanta Marie Danielle Vololontiana, Andrinirina Dave Patrick Rakotomalala. Insulin Availability and Affordability in the Urban Municipality of Antananarivo, Madagascar. International Journal of Diabetes and Endocrinology. Vol. 6, No. 1, 2021, pp. 1-4. doi: 10.11648/j.ijde.20210601.11

Received: December 13, 2020; Accepted: December 21, 2020; Published: January 12, 2021

\begin{abstract}
Background: Insulin is classified as an "essential drug". It should be available in all pharmacies at an affordable price. This remains a major problem in low income countries like ours. Aim: Our study aims to describe the insulin availability and affordability in the Urban Municipality of Antananarivo, Madagascar. Methods: It was a cross sectional study over a period of 3 months at all pharmacies existing in the Urban Municipality of Antananarivo. Insulin availability was assessed according to the classification of the World Health Organization. Affordability was assessed from the ratio between the monthly cost of insulin treatment and the Malagasy monthly health expenditure, and the ratio between the monthly cost of insulin treatment and the guaranteed minimum inter-professional wage in Madagascar. Result: We had retained 79 pharmacies. Insulin availability in private pharmacies was higher than in public hospital pharmacies. Human insulin had a high availability rate: short-acting (70.89\%) and mixed (78.08\%). Availability of analogue insulin was low: fast-acting (7.59\%) and long-acting (34.18\%). To buy insulin, a patient was spending monthly 18.75 to $236.24 \%$ of the equivalent of guaranteed minimum inter-professional wage. All pharmacies had refrigerators to store insulin. Conclusion: The availability of insulin in the Urban Municipality of Antananarivo was high while diabetic patients have low financial affordability. A good governance health policy and multisectoral actions would be necessary.
\end{abstract}

Keywords: Affordability, Availability, Insulin, Madagascar

\section{Introduction}

Diabetes mellitus is one of the leading causes of cardiovascular death [1]. The number of patients with diabetes mellitus on insulin is increasing. In fact, one in seven patients with type 2 diabetes mellitus would require insulin therapy in France [2]. A study carried out in Antananarivo showed that $76.5 \%$ of diabetics hospitalized are treated with insulin [3].

In order to improve patient care, drugs availability and affordability such as insulin is a key and strategic element of any health policy. However, it remains problematic in low-income countries, [4] like ours. Insulin is an essential life-sustaining medication for some patients with diabetes mellitus and has been classified as "an essential medication" [5]. It should therefore be available everywhere and for all the people who need it to survive. So this study aimed to describe the levels of insulin availability and affordability in the Urban Municipality of Antananarivo (UMA).

\section{Methods}

We conducted a cross-sectional study for descriptive purposes, over a three-month period (April 1 to June 30, 2017). It was carried out in the UMA, capital city of Madagascar, which covers an area of $91.5636 \mathrm{~km}^{2}$ with a population of $1,168,898$. We included in the study all pharmacies of the University Hospital Centers (public hospital pharmacies) and private pharmacies in the UMA. Pharmacies in public 
pediatric hospitals and pharmacies closed during the survey were excluded from our study. Parameters retained were pharmacy sector, different types of insulin available to the pharmacy, unit price of each type of insulin, and how to store insulin.

Classification of physical accessibility or availability of each type of insulin was made from that of the World Health Organization (WHO). Availability is very low if it is less than $30 \%$, low if between 30 and $49 \%$, high if between 50 and $80 \%$ and very high if more than $80 \%$ [6].

Assessment of financial affordability of each type of insulin was carried out from:

1. Ratio between the average monthly cost of treatment of insulin and the Malagasy monthly health expenditure. In Madagascar, health spending per capita according to the World Bank was USD 13.67 over 12 months equivalent to Malagasy Ariary (MGA) 3,700 per month in 2014. This financial affordability is poor, average and good if the costs of monthly treatment was 2 times higher, between half and double, below half of the Malagasy monthly health expenditure, respectively [7].

2. Ratio between the average monthly cost of each type of insulin and the guaranteed minimum inter-professional wage fixed at MGA 144,003 in 2016. The daily salary was MGA 7,200 counting 20 working days per month. Treatment is affordable and unaffordable if the cost of monthly treatment is less than or equal to and greater than a daily salary, respectively [7].

3. Qualitative accessibility concerned the method of storage of insulin at a temperature between $4^{\circ} \mathrm{C}$ and $10^{\circ} \mathrm{C}$ as well as their expiry dates.

Data was collected using a pre-established questionnaire. The statistical analysis was done by Epi-info TM software version 3.5.4. Data are presented as the mean for continuous variables, and numbers (percentages) for categorical variables.

\section{Results}

UMA had 81 pharmacies distributed in the 6 boroughs. During the course of the survey, 79 pharmacies were selected, divided into 73 private pharmacies and 6 public hospital pharmacies.

Overall, at least one insulin was available in $74.68 \%(59 / 79)$ of the pharmacies surveyed. By type, mixed insulin was available in 59 pharmacies $(74.68 \%)$ and short-acting insulin in 56 pharmacies $(70.89 \%)$ (Table 1$)$.

Table 1. Availability of each type of insulin in private pharmacies and public hospital pharmacies.

\begin{tabular}{|c|c|c|c|}
\hline \multirow{2}{*}{ Type of insulin } & \multicolumn{2}{|l|}{ Availability } & \multirow{2}{*}{ Overall } \\
\hline & Private pharmacies $(n=73)$ & Public hospital pharmacies $(n=6)$ & \\
\hline Fast-acting & $6(8.22 \%)$ & $0(0 \%)$ & $6(7.59 \%)$ \\
\hline Short-acting & $52(71.23 \%)$ & $4(66.67 \%)$ & $56(70.89 \%)$ \\
\hline Mixed & $55(75.34 \%)$ & $4(66.67 \%)$ & $59(74.68 \%)$ \\
\hline Intermediate-acting & $18(24.66 \%)$ & $2(33.33 \%)$ & $20(25.32 \%)$ \\
\hline Long-acting & $26(35.62 \%)$ & $1(16.67 \%)$ & $27(34.18 \%)$ \\
\hline
\end{tabular}

Only one private pharmacy had all types of insulin and no public hospital pharmacy had them.

The median unit price of each type of insulin available ranged from MGA 10,630 (INSUMAN ${ }^{\circledR}$ COMB 30, 3mL Pen) to MGA 56,700 (LANTUS SOLOSTAR $®$, $3 \mathrm{~mL}$ Pen). It was higher in private pharmacies than in public hospital pharmacies (Figure 1).

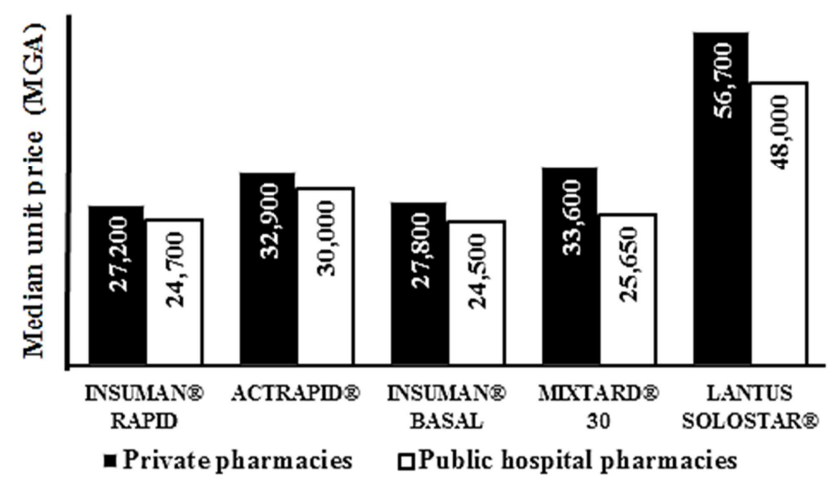

Figure 1. Comparison of median unit prices of each type of insulin between private pharmacies and public hospital pharmacies (MGA: Malagasy ariary).

All the costs of treatment of each type of insulin had largely exceeded double the Malagasy monthly health expenditure
(Table 2).

Compared to the guaranteed minimum inter-professional wage in Madagascar, patients spent 18.75 to $236.24 \%$ of their salary to buy their monthly insulin (Table 3).

Regarding the quality of insulin, all of the UMA pharmacies had refrigerators to store them.

\section{Discussion}

According to the WHO classification on drug availability [6], the availability of insulin in the pharmacies surveyed was high with a rate of $74.68 \%$ in our study. It was $75.34 \%$ at the private pharmacies and $66.67 \%$ at the public hospital pharmacies. However, in a study by Liu et al in China, it was low at the private pharmacies (less than 49\%) [8]. This good availability found in our study could be explained by the fact that it was a study conducted in the capital of our country. In fact, more than $50 \%$ of the wholesale distributor of pharmaceutical products is located in the city center (23 out of 42 wholesalers) [9].

Concerning types of insulin, our results showed that mixed insulin and short-acting insulin had a high availability (respectively $74.68 \%$ and $70.89 \%$ ) compared to long-acting insulin, intermediate-acting insulin and fast-acting insulin 
(34.18\%, 25.32\% and 7.59\% respectively). In contrast, in India, long-acting insulin $100 \mathrm{IU} / \mathrm{mL}$ and fast-acting insulin 100 $\mathrm{IU} / \mathrm{mL}$ had high availability compared to other types of insulin [10]. Likewise, in the United States of America and the United Kingdom, the use of long-acting and fast-acting insulin has been increasing since 2008. These cases have occurred thanks to clinical trials which have demonstrated the advantages of the administration of these analogue insulin, such as decreasing the risk of nocturnal hypoglycemia, and significantly reducing glycated hemoglobin [11]. Despite this, in low-income countries like ours, the prescription of insulin types mainly takes into account the financial condition of diabetic patients [12]. In addition, at the time of our investigation, the long-acting and fast-acting had not yet obtained marketing authorization in Madagascar [13]. It is therefore important to create a multi-partner working group (Ministry, Diabetes Health Non-Governmental Organization, Physicians, Central Pharmacy and patient associations) to ensure a good supply of insulin. Such a group was set up in Mali and this country benefited from it through the functioning of this group [14]. Also, the marketing authorization registration procedure should be facilitated to ensure the marketing of insulin.

Table 2. Ratio between the monthly cost of insulin treatment and the Malagasy monthly health expenditure.

\begin{tabular}{|c|c|c|c|c|c|}
\hline Type of insulin & Trade name & $\begin{array}{l}\text { Median unit price } \\
\text { (MGA) }\end{array}$ & $\begin{array}{l}\text { Number of vial or } \\
\text { pen per month }\end{array}$ & MCIT (MGA) & $\begin{array}{l}\text { Ratio MCIT / } \\
\text { MMHE }\end{array}$ \\
\hline Fast-acting & NOVORAPID ${ }^{\circledR}$ & 45,700 & 1 to 2 & 45,700 to 91,400 & 12.35 to 24.70 \\
\hline \multirow{2}{*}{ Short-acting } & INSUMAN $^{\circledR}$ RAPID & 27,000 & 1 to 2 & 27,000 to 54,000 & 7.30 to 14.5 \\
\hline & ACTRAPID $^{\circledR}$ & 32,900 & 1 to 2 & 32,900 to 65,800 & 8.89 to 17.78 \\
\hline \multirow{2}{*}{ Mixed } & INSUMAN $^{\circledR}$ COMB 30 & 10,638 & 3 to 6 & 31,914 to 63,828 & 9.2 to 18.4 \\
\hline & MIXTARD $^{\circledR} 30$ & 33,600 & 1 to 2 & 33,600 to 67,200 & 9.08 to 18.16 \\
\hline Intermediate-acting & INSUMAN $^{\circledR}$ BASAL & 27,800 & 1 to 2 & 27800 to 55,600 & 7.51 to 15.02 \\
\hline
\end{tabular}

MGA: Malagasy ariary; MCIT: monthly cost of insulin treatment; MMHE: Malagasy monthly health expenditure.

Table 3. Ratio between the monthly cost of insulin treatment and the guaranteed minimum inter-professional wage in Madagascar.

\begin{tabular}{lllll}
\hline Type of insulin & Trade name & $\begin{array}{l}\text { Median unit price } \\
\text { (MGA) }\end{array}$ & $\begin{array}{l}\text { Number of vial or } \\
\text { pen per month }\end{array}$ & $\begin{array}{l}\text { Ratio MCIT / } \\
\text { GMIW }\end{array}$ \\
\hline Fast-acting & NOVORAPID & 45,700 & 1 to 2 & 45,700 to 91,400 \\
Short-acting & INSUMAN $^{\circledR}$ RAPID & 27,000 & 1 to 2 & 27,000 to 54,000 \\
& ACTRAPID $^{\circledR}$ & 32,900 & 1 to 2 & 31.74 to 63,47 \\
Mixed & INSUMAN $^{\circledR}$ COMB $30^{\circledR}$ & 10,638 & 3 to 6 & 32,900 to 65,800 \\
Intermediate-acting & MIXTARD $^{\circledR} 30$ & 33,600 & 1 to 2 & 31,914 to 63,828 \\
Long-acting & INSUMAN $^{\circledR}$ BASAL & 27,800 & 1 to 2 & 33,600 to 67,200 \\
\hline
\end{tabular}

MGA: Malagasy ariary; MCIT: monthly cost of insulin treatment; GMIW: guaranteed minimum inter-professional wage.

In our study, like the literature [10], analogues insulin were two to five times more expensive than human insulin. Insulin available from private pharmacies were sold at a higher price than those of public hospital pharmacies. Indeed, the median percentage of cumulative price margin is $18 \%$ in the public sector and $20 \%$ in the private sector for a essential drugs [15]. This could explain this difference in insulin prices. A meta-analysis conducted by Beran and Yudkin had shown the same observation, especially in low-income countries [16]. Compared to the Malagasy monthly health expenditure, the costs of monthly insulin treatment varied from 7.30 to 91.94 times in our series. The affordability of insulin treatment was therefore poor. Compared to the guaranteed minimum inter-professional wage in Madagascar, insulin therapy was unaffordable (18.75 to $236.24 \%$ ), in our study. In Mali and Vietnam, patients with diabetes mellitus respectively spent $38 \%$ and $39 \%$ of their salary to buy insulin [16]. In addition, all insulin marketed in our country come from abroad. The existence of the import duty affects the price of insulin imported into our country and therefore the final selling price of insulin. This could limit access to those on low incomes [17]. Given the poverty rate over $70 \%$ in
Madagascar [18] and the increasing price of insulin in worldwide [19], financial inaccessibility will remain a major challenge in low-income countries like ours. Establishment of universal health coverage would therefore be essential.

In our study, even if all pharmacies had insulin storage refrigerators, the possibility of poor conservation is possible. Indeed, the existence of regular power cuts constitutes an important barrier for the storage of insulin in low-income countries [20].

However, respecting the cold chain is essential to ensure the good quality of insulin [21].

\section{Conclusion}

In the urban municipality of Antananarivo, "the capital of Madagascar", the availability of insulin in public hospital pharmacies and private pharmacies was high. However, the affordability of insulin for our patients with diabetes mellitus was low. Similarly, their good conservation remains uncertain due to frequent power cuts. The reasons for the high price of insulin are not fully determined. Are these factors related to the production, the lack of competition from generic manufacturers, or the 
strength of three multinational insulin companies? However, the problem of access to insulin is not unsurpassable. A policy of good governance and multisectoral action within the different ministries of each country will therefore be necessary.

\section{Competing Interests}

The authors declare that they have no competing interests.

\section{References}

[1] Martín-Timón I, Sevillano-Collantes C, Segura-Galindo A, et al. Type 2 diabetes and cardiovascular disease: Have all risk factors the same strength? World J Diabetes. 2014; 5 (4): 444-70.

[2] Charbonnel B, Penfornis A, Varroud-Vial M, Kusnik-Joinville O, Detournay B. Insulin therapy for diabetes mellitus: Treatment regimens and associated costs. Diabetes Metab. 2012; 38: 156-163.

[3] Raherison RE, Ramilitiana B, Raharinavalona SA, Rakotomalala DP. New diabetics seen in Joseph Raseta Befelatanana Hospital of Antananarivo (2002-2003). Rev. méd. Madag. 2015; 5 (1): 526-30.

[4] Ewen M, Joosse H-J, Beran D, et al. Insulin prices, availability and affordability in 13 low-income and middle-income countries. BMJ Global Health 2019; 4: e001410.

[5] Ashcroft RE. Access to essential medicines: A hobbesian social contract approach. Dev World Bioeth. 2005; 5 (2): 121-41.

[6] World Health Organization, Regional office for the Eastern Mediterranean. [Online]. Price, availability and affordability: an international comparison of chronic disease medicines. 2006. [Acces January 11, 2019]. Available on: http://apps.who.int/iris/handle/10665/116493.

[7] World Health Organization, Health Action International. [Online]. Measuring medecine price, availability, affordability and price components. 2006; 2nd edition. 7. World Health Organization. [Acces January 11, 2019]. Available on: http://apps.who.int/iris/handle/10665/70013.

[8] Liu C, Zhang X, Liu C, Ewen M, Zhang Z, Liu G. Insulin prices, availability and affordability: a cross-sectional survey of pharmacies in Hubei Province, China. BMC Health Serv Res. 2017; 17 (597): 1-9.
[9] Madagascar Medicines Agency (AMM). List of pharmaceutical wholesalers [Online]. AMM; 2017. [Acces June 05, 2018]. Available on: http://www.agmed.mg/Pdf/Grossistes_Madagascar.pdf.

[10] Sharma A, Kaplan WA. Challenges constraining access to insulin in the private-sector market of Delhi, India. BMJ Glob Heal. 2016; 1: 1-13.

[11] Sanlioglu AD, Altunbas HA, Balci MK, Griffith TS, Sanlioglu S. Clinical utility of insulin and insulin analogs. Islets. 2013; 5 (2): 67-78.

[12] Beran D, Ewen M, Laing R. Constraints and challenges in access to insulin: a global perspective. Lancet Diabetes Endocrinol. 2016; 4: 275-85.

[13] Madagascar Medicines Agency (AMM). List of medicines registered in Madagascar by holders of A. M. M. [Online]. AMM; 2018. [Acces June 05, 2018]. Available on: http://www.agmed.mg/Pdf/Liste_AMM_Valid.pdf.

[14] Beran D, Miranda JJ, Cardenas MK, Bigdeli M. Health systems research for policy change: lessons from the implementation of rapid assessment protocols for diabetes in low- and middle-income settings. Heal Res Policy Syst. 2015; 13 (41): $1-10$.

[15] Ministry of Public Health (MSANP). Country pharmaceutical profile. Madagascar: MSANP; 2011.

[16] Beran D, Yudkin JS. Looking beyond the issue of access to insulin : What is needed for proper diabetes care in resource poor settings. Diabetes Res Clin Pract. 2010; 88 (3): 217-21.

[17] Kaplan W. Insulin tarifs and taxes profile. Amsterdam: Health Action International; 2016.

[18] Belghith NBH, Randriankolona PL, Osborne T. Madagascar Poverty and Inequality Update: Recent Trends in Welfare, Employment, and Vulnerability. International Bank for Reconstruction and Development/The World Bank. 2016.

[19] Cefalu WT, Dawes DE, Gavlak G et al. Insulin Access and Affordability Working Group: Conclusions and Recommendations Diabetes Care 2018; 41: 1299-1311.

[20] Besançon S, Beran D, Bouenizabila É. Access to insulin in developing countries: A complex issue. MmM. 2014; 8 (2): 153-7.

[21] Gill G V. Stability of insulin in tropical countries. Trop Med Int Heal. 2000; 5 (9): 666-7. 